\title{
COMMENTARY
}

\section{The nutritional energy to clinical outcome relation revisited}

\author{
Michael P Casaer
}

See related research by Bellomo et al., http://ccforum.com/content/18/2/R45

\begin{abstract}
In the previous issue of Critical Care, Dr Bellomo and colleagues reported an observational study of the relationship between nutritional intake and survival in the RENAL randomized controlled trial. In summary, the total energy intake in a very large and severely ill patient population was low. Higher average daily caloric energy intake was not associated with improved survival. The study illustrates the complexity of the interaction between disease and nutrition.
\end{abstract}

The observational study by Bellomo and colleagues [1] is valuable for clinicians and investigators involved in ICU nutrition for two reasons. First, it provides an unbiased snapshot of nutrition therapy in severe critical illness during 2005 to 2008 in Australia and New Zealand. Indeed, the risk for selection bias in this nutritional dataset is very low. In the RENAL (Randomized Evaluation of Normal vs. Augmented Level of Replacement Therapy) randomized controlled trial $(\mathrm{RCT}), 89 \%(n=1,508)$ of eligible patients were effectively randomized [2]. In $97 \%$ of these RENAL patients, prospectively collected nutrition energy data were complete. The administered energy (including nonnutritional energy) was low (mean $11 \mathrm{kcal} / \mathrm{kg} /$ day) despite $30 \%$ of patients receiving (total or supplemental) parenteral nutrition. Moreover, 1 week was needed to achieve full feeding in this real-life ICU situation.

Second, this observational study of the relation between nutritional intake and 90-day survival may contribute to generating new hypotheses and to designing new nutrition RCTs in the ICU. Indeed, the optimistic expectations for improved outcome by enhanced (enteral or parenteral) nutrition in the ICU have been dismissed by recent RCTs [3-7]. The duration of ICU dependency, survival and

Correspondence: michael.casaer@uzleuven.be

Clinical Department and Laboratory of Intensive Care Medicine, KU Leuven, Herestraat 49, B-3000 Leuven, Belgium functional outcome were unaffected or even worsened by different early feeding interventions. This finding has inspired investigation of nutritional data available from previous non-nutritional RCTs (Figure 1). Multicenter surveys of nutrition practices predict an impressive mortality reduction of more than $30 \%$ per additional $1,000 \mathrm{kcal}$ mean daily caloric intake (DCI) achieved [8,9]. RENAL nutrition data [1] and Glucontrol nutrition data [10], on the contrary, suggest a neutral relation between DCI and survival or even increased mortality with more nutrition (Figure 1). The VISEP (Efficacy of Volume Substitution and Insulin Therapy in Severe Sepsis) trial also showed that patients receiving only enteral nutrition experienced a better survival despite much less nutritional energy administered [11]. Likewise, the lowest energy intake interval was associated with the fastest recovery in an observational analysis of enteral plus parenteral energy in the EPaNIC (Impact of Early Parenteral Nutrition Completing Enteral Nutrition in Adult Critically Ill Patients) trial, even in the "late" arm where patients did not receive any parenteral nutrition during the first week in the ICU [12].

Dr Bellomo and coauthors avoided several common problems with observational studies of nutrition in the ICU. First, as explained above, the analyses were performed in a large unselected group of severely ill patients, reducing the risk of nutritional selection bias. Time bias is a second problem with analyses of the association between clinical outcome and average energy intake, as the provision of nutrition improves during ICU stay [13]. The authors therefore provided a separate analysis restricted to patients staying longer than 3 days in the ICU to tackle this problem. In this substudy, Kaplan-Meier analysis revealed a higher mortality in patients with higher DCI [1]! A third, often unrecognized error is informative censoring in time-to-event analyses [13]. Informative censoring occurs, for example, when patients leaving the ICU earlier are censored in ICU survival analyses on the ICU discharge day. This statistical flaw artificially inflates the observed mortality in patient 


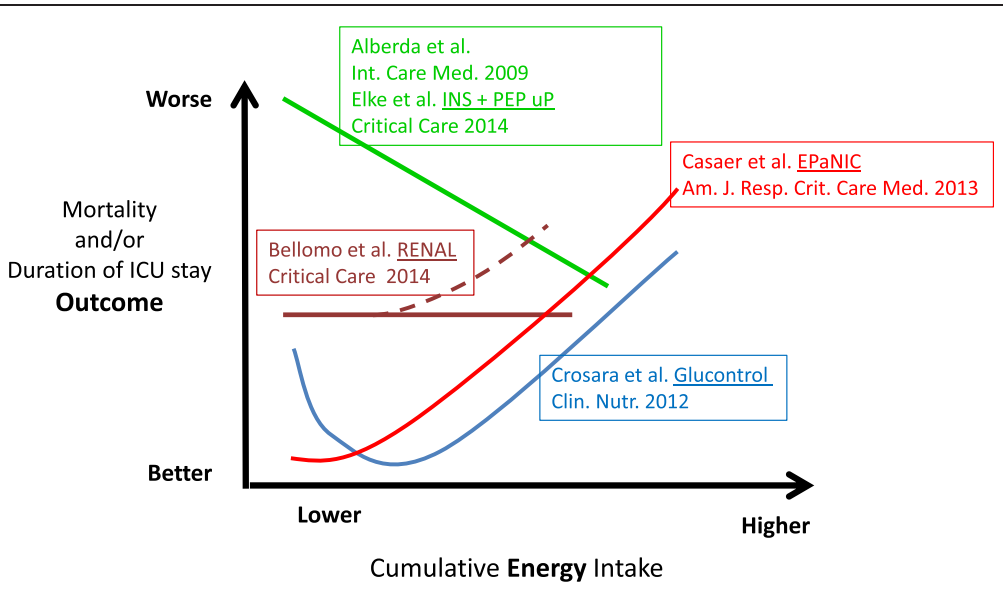

Figure 1 Schematic conceptual graph depicting the energy to clinical outcome relationship as suggested by different observational analyses. For analyses, see [1,8-10,12]. EPaNIC, Impact of Early Parenteral Nutrition Completing Enteral Nutrition in Adult Critically III Patients; INS + PEP UP, International Nutrition Survey (INS) Enhanced Protein-Energy Provision via the Enteral Route in Critically III Patients (PEP uP); RENAL, Randomized Evaluation of Normal vs. Augmented Level of Replacement Therapy.

groups experiencing a shorter ICU stay [13]. Bellomo and colleagues avoided this problem by using landmark 90-day-survival independent of ICU or hospital discharge status [1]. With this undisputable mortality endpoint, moreover, assessment bias is very unlikely. Nevertheless, this endpoint is also a limitation, because long-term functional outcome - perhaps more likely to be affected by nutrition - was not reported.

Finally, it is impossible to distinguish in an observational study whether less severely ill patients are easier to feed or whether better feeding improves outcome. Indeed, at baseline the patients in the lower DCI group had more organ failure and were older. However, the results of unadjusted and the multiple adjusted analyses all point robustly in the same direction, even if two (mean and median) energy variables together in one multivariable model might be too much. Ultimately, a RCT allocating patients to different energy intake levels remains the only definite solution to distinguish between cause and consequence [3].

If future RCTs confirm the impossibility to improve survival or functional outcome through enhanced feeding early in critical illness [3-7], the mechanisms behind this failure need to be unraveled to improve therapy. In the past, hyperglycemia might have been an explanation for the complications with early feeding - particularly parenteral feeding - in critical illness. Today, hyperglycemia is less likely to be an issue because almost all ICUs (87.2\%) implement a glycemic control protocol (see additional online material with [9]). Alternatively, suppression of autophagy might nullify potential benefits of early and enhanced nutrition [14,15]. Autophagy is an intracellular mechanism eliminating damaged organelles and toxic protein aggregates. Autophagy is crucial in maintaining tissue integrity, it is activated by starvation and cellular stress signals and is inhibited by feeding.

In conclusion, observational studies of prospectively collected nutritional data are valuable to designing new RCTs aimed at establishing safe and effective feeding strategies in the ICU. Such RCTs should preferably assess impact on 90-day landmark survival, acute cellular metabolism and long-term functional outcome.

\section{Abbreviations}

DCl: mean daily caloric intake; EPaNIC: Impact of Early Parenteral Nutrition Completing Enteral Nutrition in Adult Critically III Patients; RCT: randomized controlled trial; RENAL: Randomized Evaluation of Normal vs. Augmented Level of Replacement Therapy; VISEP: Efficacy of Volume Substitution and Insulin Therapy in Severe Sepsis.

\section{Competing interests}

Baxter Healthcare provided an unrestrictive research grant to KU Leuven covering less than one-third of the costs of the clinical EPaNIC trial. MPC received doctoral research support from the Flemish Government (FWO), postdoctoral research support from the Catholic Universities Leuven (KOF) and a speaker's fee from Baxter Belgium.

\section{Published: 07 May 2014}

\section{References}

1. Bellomo R, Cass A, Cole L, Finfer S, Gallagher M, Lee J, Lo S, McArthur C, McGuiness S, Myburgh J, Norton R, Scheinkestel C: Calorie intake and patient outcomes in severe acute kidney injury: findings from The Randomized Evaluation of Normal vs. Augmented Level of Replacement Therapy (RENAL) study trial. Crit Care 2014, 18:R45.

2. Bellomo R, Cass A, Cole L, Finfer S, Gallagher M, Lo S, McArthur C, McGuinness S, Myburgh J, Norton R, Scheinkestel C, Su S: Intensity of continuous renal-replacement therapy in critically ill patients. N Engl J Med 2009, 361:1627-1638.

3. Rice TW, Wheeler AP, Thompson BT, Steingrub J, Hite RD, Moss M, Morris A, Dong N, Rock P: Initial trophic vs full enteral feeding in patients with acute lung injury: the EDEN randomized trial. JAMA 2012, 307:795-803.

4. Heidegger CP, Berger MM, Graf S, Zingg W, Darmon P, Costanza MC, Thibault R, Pichard C: Optimisation of energy provision with supplemental parenteral nutrition in critically ill patients: a randomised controlled clinical trial. Lancet 2013, 381:385-393. 
5. Doig GS, Simpson F, Sweetman EA, Finfer SR, Cooper DJ, Heighes PT, Davies AR, O'Leary M, Solano T, Peake S: Early parenteral nutrition in critically ill patients with short-term relative contraindications to early enteral nutrition: a randomized controlled trial. JAMA 2013, 309:2130-2138,

6. Needham DM, Dinglas VD, Morris PE, Jackson JC, Hough CL, Mendez-Tellez PA, Wozniak AW, Colantuoni E, Ely EW, Rice TW, Hopkins RO, for the NIH NHLBI ARDS Network: Physical and cognitive performance of acute lung injury patients one year after initial trophic vs full enteral feeding: EDEN trial follow-up. Am J Respir Crit Care Med 2013, 188:567-576.

7. Casaer MP, Mesotten D, Hermans G, Wouters PJ, Schetz M, Meyfroidt G, Van CS, Ingels C, Meersseman P, Muller J, Vlasselaers D, Debaveye Y, Desmet L, Dubois J, Van AA, Vanderheyden S, Wilmer A, Van den Berghe G: Early versus late parenteral nutrition in critically ill adults. N Engl J Med 2011, 365:506-517.

8. Alberda C, Gramlich L, Jones N, Jeejeebhoy K, Day AG, Dhaliwal R, Heyland DK: The relationship between nutritional intake and clinical outcomes in critically ill patients: results of an international multicenter observational study. Intensive Care Med 2009, 35:1728-1737.

9. Elke G, Wang M, Weiler N, Day AG, Heyland DK: Close to recommended caloric and protein intake by enteral nutrition is associated with better clinical outcome of critically ill septic patients: secondary analysis of a large international nutrition database. Crit Care 2014, 18:R29.

10. Crosara ICR, Mélot C, Preiser JC: U-shaped relationship between caloric intake and outcome of critically ill patients. Clin Nutr 2012, 7:17.

11. Elke G, Kuhnt E, Ragaller M, Schadler D, Frerichs I, Brunkhorst FM, Loffler M, Reinhart K, Weiler N: Enteral nutrition is associated with improved outcome in patients with severe sepsis. A secondary analysis of the VISEP trial. Med Klin Intensivmed Notfmed 2013, 108:223-233.

12. Casaer MP, Wilmer A, Hermans G, Wouters PJ, Mesotten D, Van den Berghe G: Role of disease and macronutrient dose in the randomized controlled EPaNIC trial: a post hoc analysis. Am J Respir Crit Care Med 2013, 187:247-255.

13. Schetz M, Casaer MP, Van den Berghe G: Does artificial nutrition improve outcome of critical illness? Crit Care, 17:302.

14. Derde S, Vanhorebeek I, Guiza F, Derese I, Gunst J, Fahrenkrog B, Martinet W, Vervenne H, Ververs EJ, Larsson L, Van den Berghe G: Early parenteral nutrition evokes a phenotype of autophagy deficiency in liver and skeletal muscle of critically ill rabbits. Endocrinology 2012, 153:2267-2276.

15. Hermans G, Casaer MP, Clerckx B, Guiza F, Vanhullebusch T, Derde S, Meersseman P, Derese I, Mesotten D, Wouters PJ, Van CS, Debaveye Y, Gosselink R, Gunst J, Wilmer A, Van den Berghe G, Vanhorebeek I: Effect of tolerating macronutrient deficit on the development of intensive-care unit acquired weakness: a subanalysis of the EPaNIC trial. Lancet Respir Med 2013, 1:621-629.

\section{$10.1186 / \operatorname{cc} 13861$}

Cite this article as: Casaer: The nutritional energy to clinical outcome relation revisited. Critical Care 2014, 18:140 